Summer 2012

\title{
Expanding the Horizons of Horizontal Inquiry into Rights Consciousness: An Engagement with David Engel
}

Michael W. McCann

University of Washington, mwmccann@u.washington.edu

Follow this and additional works at: https://www.repository.law.indiana.edu/ijgls

Part of the Constitutional Law Commons, and the International Law Commons

\section{Recommended Citation}

McCann, Michael W. (2012) "Expanding the Horizons of Horizontal Inquiry into Rights Consciousness: An Engagement with David Engel," Indiana Journal of Global Legal Studies: Vol. 19 : Iss. 2 , Article 4.

Available at: https://www.repository.law.indiana.edu/ijgls/vol19/iss2/4

This Comment is brought to you for free and open access by the Law School Journals at Digital Repository @ Maurer Law. It has been accepted for inclusion in Indiana Journal of Global Legal Studies by an authorized editor of Digital Repository @ Maurer Law. For more information, please contact rvaughan@indiana.edu.

\section{$\Psi$}

JEROME HALL LAW LIBRARY

INDIANA UNIVERSITY

Maurer School of Law
Blooming ton 


\title{
Expanding the Horizons' ${ }^{1}$ of Horizontal Inquiry into Rights Consciousness: An Engagement with David Engel
}

\author{
MICHAEL MCCANN*
}

\begin{abstract}
This Comment interprets and reflects on the key features of David Engel's argument about the importance of balancing vertical models of rights diffusion with horizontal ethnographic studies of how rights consciousness develops out of practical experience in everyday social contexts. The primary focus is on endorsing the general argument and amplifying some understated or undeveloped dimensions of Engel's position. In particular, this reflection makes the case for: 1) expanding the range of subjects and contexts subjected to horizontal study, including especially greater attention to "haves" and elite actors; 2) studying subjects expected to have high rights consciousness as well as those likely to demonstrate low rights consciousness so as to develop more comparative theorizing; 3) adding more refined sociological analysis of context and power to the ethnographic study of subject consciousness, again to advance comparative theorizing about factors that encourage or discourage rights consciousness; and 4) to sharpen attention to variations in the substantive content as well as relative salience of rights consciousness among subjects, which in turn may disrupt assumptions about the assumed automatic identification of rights discourses with neoliberal hegemony. Many examples from sociolegal scholarship are cited to illustrate and support the various analytical points.
\end{abstract}

- Gordon Hirabayashi Professor for the Advancement of Citizenship, University of Washington. I would like to thank David Engel for a splendid article and Angelina Godoy, Arzoo Osanloo, Bernadette Atuahene, and David Engel for conversations and comments about my response. This Article was written while I was a Fellow in the Law and Public Affairs program at Princeton University.

1. The Free Online Dictionary defines "horizon" as " $t]$ he apparent intersection of the earth and sky as seen by an observer." Horizon Definition, THEFREEDICTIONARY.COM, http://www.thefreedictionary.com/horizon (last visited Feb. 26, 2012).

Indiana Journal of Global Legal Studies Vol. 19 \#2 (Summer 2012)

(C) Indiana University Maurer School of Law 


\section{INTRODUCTION}

David Engel has enlightened us with another very important article about the meanings and practices of rights. This new Article builds on themes present in his important early work on Thailand, on small communities in the United States that discourage personal injury litigation, and on people with disabilities in the United States following the passage of the Americans with Disabilities Act.

However, the new Article draws directly from the fascinating findings of David and Jaruwan Engel's recent book, Tort, Custom, and Karma. In short, the Engels offer considerable evidence that injured persons in the northern Thai province of Chiangmai have actually found rights and law less meaningful for dealing with their grievances as social life has changed in the face of global economic integration. ${ }^{2}$ This conclusion flies in the face of widespread hortatory scholarly claims or approving assumptions that Western law and rights discourse are trickling down from transnational and national levels everywhere, increasingly saturating experienced social life around the globe. Where this diffusion is not evident, Engel suggests, scholars and policy elites often lament the local forces that resist or impede the benevolent expansion of rights norms and practices. Engel questions these assumptions in several respects: for ignoring the disjuncture between elite activists and ordinary people on the ground; for wrongly treating the latter as passive recipients of ideas from on high; for blaming traditional culture as an impediment to enlightened diffusion; and for overlooking the problematic limitations and costs of embracing rights as social conventions.

The key analytical contribution of Engel's Article, therefore, is in offering an alternative understanding about the processes by which consciousness and meaning develop in social life. Engel insists that most people do not construct meanings by passively internalizing exogenously produced ideas that trickle down from above. Indeed, as his opening anecdote about the official poster endorsing children's rights in the Thai schoolhouse wonderfully illustrates, elite or officially generated messages, cues, and values often are relatively meaningless or alien to the intended target populations. Instead, he argues, "individual rights consciousness derives from the intersections of a person's life experience with the particular interpretive frameworks that are available in the

2. David M. ENGEL \& JaRUWAN S. ENGEL, TORT, CUSTOM, AND KaRMA: Globalization AND LEgal CONSCIOUSNess IN THAIllaND (2010). 
social environment." 3 The development of consciousness entails a dynamic, fluid, often uneven process that builds on life experience in different social settings and in relationship to other people. Moreover, "the relevance of rights depends in large part on how individuals come to understand their own identities and on the stories they and others tell in order to make sense of their lives." 4 Engel suggests that every person's rights consciousness is as distinct and variable as that person's particular life, although his findings confirm that groups of people who share some features of a common life may display similarities in rights consciousness. In Chiangmai, after all, rights were not very meaningful for most of the "ordinary" people he interviewed. ${ }^{5}$

This analytical understanding of how rights consciousness develops in turn leads Engel to prescribe a particular method of study. Rather than tracking a vertical trickling down of ideas or explaining the obstacles to such top-down diffusion, Engel proposes that researchers adopt a horizontal perspective or methodology. In short, such a mode of inquiry focuses directly on studying ordinary people in everyday interactions, using a mix of ethnographic protocols and intensive interviewing to map their understandings, to document their actions, and to try to make sense of the linkages between experience, meaning, and practice. The Engels' book confirms that they "encouraged interviewees to provide an extended narrative covering a broad sweep of time, in which they described their lives from childhood to present and the changes that had occurred in their social environment" as well as the specific incidents surrounding their injury. ${ }^{6}$ This technique owes greatly to the creative, rigorous, and laborious methodology of exploring personal life histories to make sense of rights consciousness that Engel and Frank W. Munger developed in their marvelous book, Rights of Inclusion. ${ }^{7}$ In short, Engel feels we researchers should labor to understand ordinary people in their own terms, within the framework of personal experience and social context from which meaning is constructed over life histories. And in doing so, we should not presume that rights or other legal categories endorsed by distant elites figure prominently or consistently as meaningful dimensions of their social consciousness. At best, we should treat familiar claims about global

3. David M. Engel, Vertical and Horizontal Perspectives on Rights Consciousness, 19 IND. J. GLOBAL LEGAL STUD. 423, 427 (2012).

4. Id.

5. Id. at 435 .

6. ENGEL \& ENGEL, supra note 2 , at 13.

7. DAVID M. ENGEL \& FRANK W. MUNGER, RIGHTS OF INCLUSION: LAW AND IDENTITY IN THE LIFE STORIES OF AMERICANS with DisabiLITIES (2003). The methodology of the book is discussed most directly in the Introduction, pp. 7-9. 
diffusion of rights as a research question rather than as a settled conclusion.

In my reading, Engel thus exhibits a complex, nuanced posture toward the vertical approach. On the one hand, he does, as noted above, warn of its problematic analytical and normative assumptions regarding the diffusion of meaningful norms, concepts, and values (like rights). On the other hand, Engel does not dismiss the vertical approach as worthless or entirely wrongheaded; indeed, he praises the vertical perspective for calling attention to transnational and state level advocates of rights ideas and for generating important insights into their activities. His primary position thus is the diplomatic one of avoiding an either/or position and urging instead balance in pursuit of both vertical and horizontal approaches. Put another way, Engel wants to call attention to the distinctive contributions of horizontal perspectives and studies that can compensate for the limitations and deficiencies of vertical approaches. Although his cumulative studies in the United States and Thailand would seem to support a skeptical expectation, Engel is careful not to argue directly that he expects horizontal studies to demonstrate a less ubiquitous and uniform embrace of rights discourse and deployment than many neoliberal scholars predict. ${ }^{8}$

\section{ENGEL IS ON SOLID GROUND}

I welcome and find quite compelling virtually all of Engel's argument. I begin with his findings about low rights consciousness in the northern Thai community that he studied. As he points out, many scholars have identified a low salience of rights in individual legal consciousness among citizens even in the United States, where rights are the topic of a hallowed official national discourse. After all, Stuart Scheingold, who famously wrote in 1974 about a "myth of rights" that permeates American culture, qualified his argument in many ways. 9 Scheingold recognized that only scattered evidence supports his view and that convincingly studying deep beliefs and practical values is difficult. Moreover, Scheingold underlined that the evidence suggests

8. I am thinking in particular of three classic works: David Engel, The Oven Bird's Song: Insiders, Outsiders, and Personal Injuries in an American Community, 18 LAW \& SOC'Y REV. 551 (1984); ENGEL AND MUNGER, RIGHTS OF INCLUSION: LAW AND IDENTITY IN THE LIFE STORIES OF AMERICANS WITH DISABILITIES, supra note 7; and ENGEL AND ENGEL, TORT, CUSTOM, AND KaRMa: GlobaLIZATION AND LEgal CONSCIOUSNESS IN THAILAND, supra note 2.

9. See Stuart A. Scheingold, The Politics of Rights: LaWyers, PUblic Policy, AND POLITICAL CHANGE 13-79 (2d ed. 2004) (1974). 
that the upper and perhaps middle classes are most inclined to invoke rights while marginal groups, especially the poor and racial minorities, seem least convinced by the legitimacy of the legal system and practical value of rights discourse. ${ }^{10}$ George Lovell recently surveyed the scholarly literature on "ordinary legal consciousness" in the United States to reconsider Scheingold's thesis, and Lovell confirmed that there is still little evidence supporting the claim that a deep, active rights consciousness seems to thrive among citizens in the United States. ${ }^{11}$ From the early studies of the Civil Litigation Research Project showing that most people "lump it" (e.g., internalize blame and endure) when they suffer injury, through the legions of ethnographic inquiries into ordinary legal consciousness, Lovell concludes that there simply is little support for the assumption that rights conventions trump other discursive frameworks for meaning making. ${ }^{12}$ For one thing, rights conventions regularly compete with other moral, religious, therapeutic, technocratic, and pop discourses. Moreover, rights do not seem to figure prominently because they do not produce much practical power in action, and in fact acting on rights can be emotionally, financially, and interpersonally costly.

These findings seem to support Engel's logic. In short, people continue to choose some discursive conventions over other "available" conventions because they demonstrate greater practical power to make sense of relationships, provide resources to advance interests, and generally empower people in negotiating everyday interactions. It is this criterion of "practical utility" that is critical to the relative and shaky appeal (or lack thereof) of rights. This is the thrust of John Gilliom's study of Appalachian welfare mothers, ${ }^{13}$ Laura Beth Nielsen's study of how ordinary people think about noxious racist and sexist street harassment, ${ }^{14}$ Kristin Bumiller's argument that claiming antidiscrimination rights actually only compounds a sense of victimization, ${ }^{15}$ and Engel's study with Frank Munger demonstrating a

10. Id. at $62-79$. 2012).

11. George Lovell, The Myth of the Myth of Rights, STUD. L., POL., \& Soc'Y. (forthcoming

12. On the Civil Litigation Research Project and "lumping it," see Richard E. Miller \& Austin Sarat, Grievances, Claims, and Disputes: Assessing the Adversary Culture, 15 LAW \& SoC'Y REV. 525, 527-28 (1980-81). The wide range of scholarship that Lovell surveys is greater than what can be referenced here.

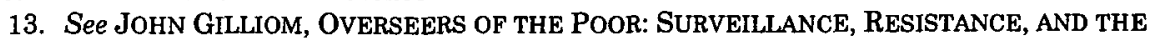
LIMITS OF PRIVACY (2001).

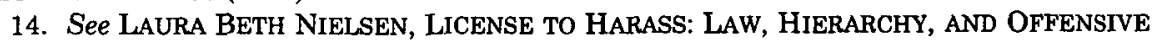
PUBLIC SPEECH (2004).

15. Kristin Bumiller, The Civil Rights Society: The Social Construction of VICTIMS 2-4 (1988). 
common, but not uniform, reluctance of people with disabilities to claim or even embrace a rights framework to deal with their challenges. ${ }^{16}$

There is evidence for this claim beyond the United States, in studies by authors other than Engel. For example, Bernadette Atuahene found that rural South African blacks felt frustrated, perplexed, and resigned after receiving none of the reparations granted by the nation's highest court for property appropriated by whites during the apartheid era. After gaining little from a judicial victory, the promise of rights as a resource simply made little sense to rural blacks exploited by whites for many generations, even in post-apartheid South Africa. ${ }^{17}$ In short, much socio-legal scholarship demonstrates not only that law in action is different from law on the books, but broad ideological exhortations by elites about the promises of rights often ring hollow at local levels to people struggling in everyday life. And if this is true within national life, Engel's finding about how transnational human rights advocacy often seems alien and relatively meaningless to ordinary people on the ground likewise seems quite plausible. As such, his exhortation to investigate whether rights constructs are prominent in the legal consciousness of ordinary people "on the ground" seems like a very sensible research agenda.

Likewise, there is much to be said for Engel's general horizontal methodology of investigating and documenting the legal consciousness of people. His primary recommendation is to talk to ordinary people in the familiar sites and spaces of routine life. In their book, the Engels interviewed several dozen people at length in hospitals where they had been treated for injuries. The goal of such interviewing was to "understand the subjectivity of the narrators-how they interpret events, how they explain their own behavior and that of others, and how they view themselves in relation to the world around them and in relation to legal norms, procedures, and institutions." 18 The focus is to probe subjects' accounts of their thinking to look for whether globalization has altered spatial and temporal frameworks, concepts of the self, relationships to others, norms and procedures related to justice, and religious values or beliefs. ${ }^{19}$ The key to sound research, again, is for

16. ENGEL \& MUNGER, supra note 7, at 4 . They summarized in the Introduction: "We wanted to interview not only those whose rights consciousness was high but those who were indifferent to rights, those who endured rather than resisted, those who were loners as well as joiners, even those who were unaware . . . about the existing legal foundations of potential rights."

17. Bernadette Atuahene \& Sanele Sibanda, The Limits of the Law: The Story of the Popela Community, Address at the Law and Society Association Annual Meeting (May 30, 2011).

18. ENGEL \& ENGEL, supra note 2, at 12-13.

19. Id. at 5-6. 
the researcher to suspend assumptions and to listen and report on what subjects relate.

Engel's methodology is a rigorous, careful version of approaches taken by many of the scholars I mention above (Gilliom, Nielsen, Atuahene, etc.) who are interested in legal consciousness from what Engel labels a horizontal perspective. That I endorse this should not be surprising to readers who recognize the similarities and differences between Engel's trademark studies and my own studies of legal mobilization by individuals and groups. ${ }^{20}$ Our approaches begin similarly from a challenge to top-down or "vertical" approaches as a way of understanding the development of legal rights consciousness. In my case, that involves challenging both judicial impact and structuralist accounts of legal meaning production. We similarly tend to focus on aggrieved persons and how they frame understandings of their grievances and the possibilities for seeking redress, as well as the actions that they take. My work is no less interested in how people develop legal consciousness over time out of practical experience negotiating a multiplicity of available cultural resources. I do not presume that legal consciousness privileges rights over other normative constructs or that formal legal action like litigation is a common, positively embraced practical option. My research questions how people think about and act in relationship to legal norms like rights. I have spent a great deal of time interviewing aggrieved citizens, probing how they think about their grievances and options, and trying to make sense of how their modes of consciousness have developed out of disputing activity over time. My earlier research probed, but did not present personal life histories much; my coauthored book, just recently begun, on immigrant Filipino workers ${ }^{21}$ makes personal history and intergenerational social history a key topic, self-consciously building on Engel's work. As such, I welcome Engel's invitation to continue that type of inquiry and his thoughtful reframing of what is required and potentially gained by the horizontal perspective.

\section{EXPANDING THE TERRAIN OF HoRIZONTAL STUdY}

Overall, I heartily endorse Engel's questions about the limits of the unilateral vertical explanation for rights diffusion and his proposal

20. See generally MICHAEL W. MCCANN, RIGHTS AT WORK: PAY EQUITY REFORM AND THE POLITICS OF LEGAL MOBILIZATION (1994).

21. The research is funded by the National Science Foundation (SES1060698) and includes George Lovell as co-principal investigator and co-author. We are planning a long book, tentatively titled $A$ Union by Law: Filipino Cannery Workers and the Trans-Pacific Struggle for Equal Rights, along with many articles on many facets of the research. 
endorsing horizontal modes of study into rights consciousness that grow out of local experience. However, I am concerned that his conceptualization of horizontal modes of study may be understood in ways that narrow the types of subjects that he locates on the proverbial ground and what we look for when we study them. My Comment thus offers several related points aiming to amplify and augment his call to expand the contours of whom, how, and what we look for in research on legal consciousness and rights practice.

\section{A. Expanding the Range of Ordinary People in Everyday Contexts Under Study}

Engel repeatedly refers to "ordinary" people in "everyday" interaction as the focal point of the horizontal methodology. But what does he mean? One plausible reading of what Engel intends to connote is that "ordinary" people are non-elites; that ordinary people are those on the lower rungs of the economic and political ladder, those with only modest status, position, and connections-perhaps even the marginalized and subaltern. This is a plausible reading of Engel because a great deal of study by scholars regarding ordinary or everyday legal consciousness is narrowly limited to a somewhat romantic enchantment with relatively low income, marginalized, individualized, and politically inactive people, thus linking ordinariness with relative powerlessness. Moreover, the fascinating case study of Thai villagers that Engel summarizes so eloquently in his Article further invites such an interpretation of his argument.

However, I call attention to Engel's appeal, made somewhat in passing, that horizontal studies could be directed toward multiple "fields of social interaction" and "broader social classes or strata," 22 And it is this point about expanding the range of people and sites of interaction subjected to horizontal study that I enthusiastically want to amplify. Indeed, we would benefit from horizontal study of corporate executives, transnational nongovernmental organization (NGO) activists, media shapers and pundits, university scholars and intellectuals, injurers and injured persons of all types, and surely those that seem potentially influential to any particular type of policy issue or community matter. Really, we ought to look at any category of social actors that we can imagine. It seems to me that an experience-based horizontal approach can be used for any strata of individuals or any setting. We need to expand studies to more types of people and especially beyond the widespread focus on the "have nots." After all, the

22. Engel, supra note 3 , at 448. 
"haves" exercise great institutional power and exploring their rights consciousness (or lack thereof) is important for understanding how law constrains or facilitates the exercise of that social power. Such studies can go a long way to testing the famous claim by E.P. Thompson that "[t] he rhetoric and the rules of a society are something a great deal more than a sham .... They may disguise the true realities of power, but, at the same time, they may curb that power and check its intrusions." 23

And there is no reason why such studies need to be joined to the vertical perspective about top-down diffusion and passive internalization. I again agree with Engel that one of the most interesting features of Sally Merry's book Human Rights and Gender Violence $^{24}$ is the ethnography of transnational and cosmopolitan human rights activists. Merry wanted to know how they think and why and how their legal consciousness emerged amidst the particular types of structured interactions and experiences. Merry seems every bit as interested in how the "rights consciousness" of NGO activists "derives from the intersections of a person's life experience with the particular interpretive frameworks that are available in the social environment." 25 In short, she offers a compelling horizontal study of those activists and how they developed their particular legal consciousness that is relatively independent of the problematic vertical assumptions that she, as Engel insightfully argues, exhibits about top-down diffusion or translation at "lower" local levels. In their own collectively experienced worlds, the legal consciousness of transnational activists and how they construct meaning is as ordinary and everyday as it is for villagers.

Only by expanding the range of actors whom we study horizontally can we begin to develop a more comparative and analytically refined understanding of how the experiences of different subjects do or do not engage with law and rights. Moreover, in any ongoing dispute or public policy matter, it makes sense to understand the legal consciousness and constructed legal claims of all parties prominently involved in the ongoing interactive relationship. This can facilitate a shift from a unilateral focus on the rights consciousness of the injured to a more multilevel and interactive understanding of the variety of rights orientations-including those where rights figure only weakly or not at all-in a potential or developing contentious relationship involving injury. This is as important for the variously situated actors that might have a stake in issues of liability for harm and potential redress as it is for the injured, upon whom Engel focuses.

23. E.P. ThOMPSON, WHIGS AND HUNTERS: THE ORIGIN OF THE BLACK ACT 265 (1975).

24. Sally Engle Merry, Human Rights and Gender Violence: Translating INTERNATIONAL LAW INTO LOCAL JUSTICE (2006).

25. Engel, supra note 3, at 427. 


\section{B. The Importance of Studying Ordinary Rights Activists}

While Engel does point to such an enlarged range of subjects and sites that deserve horizontal study, he also gestures toward distinctions between ordinary practices of ordinary people "on the ground" and those of rights activists, advocates, or movement leaders, including NGO activists who are Thai, American, or European. ${ }^{26}$ The distinction seems to turn on the assumption that the latter embrace rights and thus inhabit what Barbara Yngvesson has called the "imaginary of neoliberal culture." 27 These distinctions make sense in the context of his argument challenging the assumptions of vertical diffusion models of rights consciousness. And it is important to repeat that Engel does not exclude in advance the possibility that ordinary people find rights meaningful. That said, I offer here a slightly different, if complementary view that underlines the importance of self-consciously studying ordinary people who are rights activists on the ground and the ways in which they often challenge rather than embrace neoliberal ideas and values.

It is relevant to note that most of the subjects whom I, as a political scientist, study are engaged in struggles over rights and are to some extent advocates of rights; I sometimes refer to them as "activists." 28

Indeed, I take disputes over rights as a criterion of research case study selection, although I try not to presume that individual subjects engaged in or affected by such struggles are necessarily or uniformly invested in rights as a meaningful cultural discourse. And most of my studies find a range of variation in consciousness about law and, specifically, rights, although my case selection criteria lead to more people in the "high rights consciousness" end of the continuum than one finds in most of Engel's work. Most of these rights activists that I encounter tend to be very ordinary people, and rights grow from very familiar everyday contexts of community life. For example, most of the women I studied for my book Rights at Work were making very low wages, were variably educated, and were typically from working class families. Moreover, my interviews revealed that for most of their lives many never thought of themselves as feminists or rights activists and did not think much about rights at all. They were underpaid working or lower middle-class women, stuck in local contexts and resigned to deadend economic situations that seemed normal and thus perhaps beyond change. Many of them also worked for significant periods in offices where posters celebrating rights hung, largely unnoticed and lacking in salient meaning, much like the Thai students in Engel's anecdote.

26. Engel, supra note 3, at 446-47.

27. Id. at 455 .

28. See MCCANN, supra note 20. 
Indeed, systematic study of their life histories almost surely would provide little clue into their rapid development of a quite deep and robust rights consciousness.

However, I documented dramatic changes in the rights consciousness of many working women that followed from social and political changes in the women's immediate, local environment. These included failures in workplace collective bargaining, intransigent obstacles to job advancement, increasing hardships amidst tough economic times, escalating talk about rights among peer workers and union shop stewards, and some small disputes that escalated to aggravate a sense of grievance. For some women, going through a divorce-how ordinary and everyday in America!-was the first step in shifting from a very low to high rights consciousness, and often the transition was extremely rapid. Lawyers were sometimes involved, but they rarely seemed very influential to most people I interviewed, at least in any direct way; indeed, lawyers were viewed warily. What changed these women was not the routine character of their social position or elite messaging, but rather changes in the social environment to which they responded, in the process stimulating or amplifying new facets of rights consciousness that added new chapters to their personal histories. And even as many became "activists," or even "leaders," they remained extremely ordinary people. They were still poorly paid, still experienced few opportunities for advancement at work, and still devoted Friday nights to the bowling league or kids' school events as the weekend indulgence. Although, many did gain some self-respect and respect from others and also added new routines in their modes of thinking and practice that reflected the enhanced salience of rights, there is nothing extraordinary and much that is everyday about such episodes of rights-based engagement. Once the context of disputing deescalated and opportunities for challenge were eclipsed by developments near and far, many of the subjects I studied settled down into activity where rights took on uncertain, variable positions in their practical activity.

These changes in rights consciousness of women in the pay equity story were relatively sudden, but sometimes shifts are more slow, and incremental, as Engel suggests. This is well exemplified by my current study with George Lovell of immigrant Filipino cannery workers. Much of our historical work about the first generation of poor immigrants in pre-Cold War America is grounded in archived personal correspondence, union meeting minutes, memoirs, and the like. The fictionalized autobiography of Carlos Bulosan, himself a peasant in the colonial Philippines who immigrated to work in the United States mainland, provides a wonderful supplement to these archives. The first half of 
Bulosan's narrative documents the transition from life in a rural homeland village to the experience of an exploited migrant worker subjected to ceaseless racist subjugation, violence, harassment, and fear. For him, to be a Filipino in America is to be a criminal based on his past of being a "union propagandist/agitator and nomadic exile: '. . . I feel like a criminal running away from a crime I did not commit. And the crime is that I am a Filipino in America . . . It was now the year (1941) of the great hatred; the lives of Filipinos were cheaper than those of dogs." 29

If low status and powerlessness connote ordinariness in much of the scholarship on legal consciousness, Filipinos were among the most ordinary denizens of America at the time. It is relevant that Bulosan recounts in detail the subjugation directly and indirectly felt at the hands of U.S. law; law came after him and his fellow immigrants, and their primary response was to run, evade, and hide rather than to reach out for law. Indeed, the word "rights" does not even show up in his famous chronicle, American is in the Heart, until the second half of the narrative, as Allos (the lead character) and his friends become involved in organizing for a union and other political solidarity associations. He found meaning in rights through collective action and communal connection-with his Filipino brothers in the union they built, in the strongly rights-oriented leftist International Longshore and Warehouse Union (ILWU) that eventually took them as an affiliate, and in the groups allied with the Popular Front that began to embrace the promises of universal human rights to challenge expanding imperialism and capitalism. All this time, Bulosan, like his colleagues, remained poor, homeless, migratory, and increasingly overtaken by illness.

One important point that we underline by historical analysis of the Filipino experience is that the immigrants did not reach out for law until after law brutalized them. Their eventual embrace of legal tactics and rights claims, including in regular local litigation and various moments of high stakes federal litigation, was largely a desperate defensive gambit to avoid incarceration, deportation, and vigilante violence, as well as to open opportunities to marry whites, own property, and organize a union. They eventually became extremely legalistic in fighting off repression during the era of McCarthyism, taking extreme measures to organize internally along highly legalistic, rule-bound, and procedurally rigorous lines, again largely to protect themselves and elevate their status as good citizens even while they mobilized as

29. CARlos BUlosan, ON BECOMing FIlipino 9 (E. San Juan, Jr. ed., 1995) (emphasis added) (quoting CARLos Bulosan, Sound of FALLING Light: LETTERS IN EXILE 199 (Delores Feria ed., 1960)). 
advocates for socialist transformation. ${ }^{30}$ In this regard, legal rights were not just one of many available cultural resources from which to choose; they were a necessary tool to challenge the extremely repressive law imposed on them by legal elites and dominant groups, the only resource initially available to the isolated immigrants for challenging unjust violence and to create a space for political organization. Consistent with Engel, studying the histories of these immigrants is critical to understanding how they developed a rights consciousness and how that consciousness increasingly became a source of defiant, progressive activism against repressive and liberal law alike.

Following from Lovell's analysis of studies about legal consciousness in the United States, I repeat: precisely because there is reason to expect that many people are unengaged in rights struggles, we should embrace studies of those who do take rights seriously in order to understand better how and when this sometimes happens and what it means. A comparatively oriented approach to rights consciousness makes this agenda imperative. ${ }^{31} \mathrm{I}$ doubt that Engel would disagree with this claim, and in fact his Article may invite such agreement, but it bears amplification.

\section{More Sociology and Power, Please}

These insights in turn raise a related set of points regarding how horizontal study should be designed. Taking seriously Engel's invocation to focus on the ordinary and everyday lives suggests the need for a more refined, sophisticated sociological vernacular for defining different groups of subjects or subject positions, and for analyzing the social environment from which their experiences develop over time. The difference between Merry's NGO activists and Thai villagers is not just

30. This empirical story will be developed in our developing book, A UNION BY LAW. See Michael McCann \& George Lovell, Beyond Legal Mobilization: Rethinking Rights and Power (2004) (unpublished manuscript) (on file with author) (an early version of this account). See also Ron Chew, Remembering SILme Domingo And Gene Viernes: The LEGACY OF FILIPINO AMERICAN LABOR ACTIVISM (2012).

31. A splendid example of focusing on rights claiming and resistance by ordinary people, studied from a horizontal perspective, are the essays in ENGAGING THE LAW IN China: STATE, SocietY AND Possibilities For JUSTICE (Neil J. Diamant et al. eds., 2005). The essays by Kevin J. O'Brien on the "rightful resistance" of peasants and by Diamant on rights mobilization of rural women are particularly relevant to my discussion. Kevin J. O'Brien, Law and Society in the People's Republic of China, in id. at 1; Kevin J. O'Brien, Suing the Local State: Administrative Litigation in Rural China, in id. at 31; Neil J. Diamant, Hollow Glory: The Politics of Rights and Identity Among PRC Veterans in the 1950s, in id. at 131. 
the degrees of meaning they accorded to rights, but the quite different social environments and relationships to other people that shaped their experience and development of consciousness.

Both Engel and Merry provide useful descriptions of the social contexts of Thai villagers and NGO activists, but many potentially relevant factors are left out of those discussions. The factors that are addressed are not informed much by trying to identify, in general terms, the features of organized social life that make sense of specific social positions. ${ }^{32}$ We would benefit from analysis that helps to parse the form and character of these subjects' significant relationships to other persons; the institutional forces that support or silence their various discourses and practices; the modes of relative dependence or independence on one another; and the other factors that help to make sense of the conditions from which different types of legal consciousness develop. Engel does, of course, compellingly invoke changing work life that follows global economic organization to help explain weakening village norms. However, other factors are likely to matter as well, and some effort to identify discrete factors in more generalizable and systematic terms is worthwhile. It is important to underline that I am not endorsing the positivistic goal of specifying such variables so as to enable predictions about consciousness based on analysis of social position and organizational context. Indeed, my own work challenges such structural determinism. However, I do think that a more refined approach to analyzing the latter can help to make sense of the former. ${ }^{33}$ Engel and Merry make important steps in that direction, and I only urge more. The motivation is that only by such analytical inquiry can we develop a more richly comparative understanding about the social construction of rights consciousness and meaning. Additionally, if changes in subject position and context significantly alter consciousness and action regarding rights, then careful analysis is necessary to help explain the transformation. In short, I urge the integration of more sociological analysis along with the ethnographic inquiry into experience and meaning.

32. To their credit, the Engels include "Community, Social Networks, and Relationships" as one of the five subjects they investigated regarding the effects of globalization on legal culture. ENGEL \& ENGEL, supra note 2, at 5. Among the many sociological categories that might be developed to inform such analysis of subject position, I would strongly urge "class," wealth, wealth source, and status. See Carroll Seron \& Frank Munger, Law and Inequality: Race, Gender... and, of Course, Class, 22 ANN. REv. Soc. 187 (1996).

33. In RIGHTS AT WORK: PAY EQUITY AND THE POLITICS OF LEGAL MOBILIZATION, I use a framework reconstructed from social movement theory, emphasizing various types of resources and opportunities that did or not shape possibilities for action. See MCCANN, supra note 20. 
Moreover, a major difference between Engel's mode of horizontal study and the seemingly similar type of study that I and some other scholars undertake is Engel's relative inattention to matters of power. Or more precisely, I discern implications of power throughout his new Article, and much of his earlier work, but Engel seems disinclined to make much of them in explicit terms. Take, for example, Engel's intriguing discussion about how Thai villagers continued to find rights a relatively alien or meaningless discourse, while meanwhile also no longer finding norms and conventions that once inhered in the local village culture very meaningful or helpful when seeking redress for injuries. $^{34}$

That strikes me as a statement about increasing powerlessness, in the manner analyzed by sociologists like John Gaventa and many scholars who study domination and the possibilities of resistance. ${ }^{35}$ Moreover, Engel's Article could probe questions regarding whether this powerlessness to deal with injury extended to other facets of social life. For example, was anyone else either benefiting from or being empowered by these types of developments? Was economic power of these or other subjects increasing due to global economic integration even as power to redress injury declined, or are these related dimensions of disempowerment? Is this another story about the advance of global corporate power and decreasing resources of those dependent on such power? My understanding of power refers not just to the instrumental capacities of individuals, but also to the power of institutional arrangements, relationships among groups, and discourses and ideas that shape possible agendas. ${ }^{36}$ Put another way, developing greater focus on power would add a political dimension to go along with the sociological dimension urged previously to make sense of context for experience in comparative terms.

This is especially true because Engel does not contest that information, narratives, discourses, and values are increasingly produced by mass corporate organizations and groups at national and transnational levels for consumption at distant local sites. This fact makes careful analysis of the multiple layers of cultural knowledge production that converge at any site relevant. I offer an example from a

34. The Engels do mention "power" a few times in their book, mostly to refer to unequal wealth, position, or status, but "power" is not developed as a conceptual framework. ENGEL \& ENGEL, supra note 2.

35. E.g., John Gaventa, PoWER AND Powerlessness: Quiescence AND REBELlion IN AN APPALACHIAN VALLEY (1980).

36. My own work draws heavily on various adaptations of the three-dimensional model of power outlined by Steven Lukes and applied by Gaventa. See STEVEN LUKES, POWER: A RADICAL VIEW (1974); GAVENTA, supra note 35. 
previous well-known study by Engel that greatly influenced my own subsequent research and teaching. In my all-time favorite article on socio-legal issues, "The Oven Bird's Song," Engel presented evidence about how community pressure by insiders discouraged personal injury litigation and rights claiming, which was defined as anti-communitarian behavior characteristic of "outsiders," in a Midwestern suburban site he renamed Sander County. ${ }^{37}$ It is a marvelous study of how legal norms are constructed in ways that discourage and even stigmatize rights claiming by citizens, which especially disadvantaged lower income newcomers with little social status or connections to powerful insiders. Again, while the story is arguably very much about power, Engel does not frame it directly that way. The ways in which these dynamics privileged insider elites over other insiders is hinted at, but not developed by Engel. Moreover, Engel was very careful to underline that these dynamics were uniquely internal to a local, rural community in transition, largely removed from organized cultural and economic forces at the national, much less global, level.

However, some years later, William Haltom and $I^{38}$ found that these very same dynamics of stigmatizing rights claiming for redress of personal injuries were evident since the late 1970s across the nation. Moreover, we traced the sources of the key ideas and norms discouraging rights claiming to the convergence of well-funded campaigns by large scale mega-corporations, the national news media, and the long privileged cultural ideology of individual responsibility that was actively mobilized to wage the national "culture wars." In short, Engel's compelling story of rural community dynamics looks far less parochial and localized when analysis focusing on national level organizational and ideological forces are introduced. When one looks at the forms of organized power that privilege some and discourage others "available ideas" appear different.

It is relevant in this regard that we were very careful to resist claiming that these larger forces from "above" were directly shaping the legal consciousness of variously situated citizens, while also saturating popular culture at many levels. While there was scattered evidence of various types to confirm some significant but variable impact, we insisted that different types of studies-very much like those that Engel now labels "horizontal"-would be necessary to discern actual transformations in legal consciousness. My point here is that rejecting a simplistic vertical diffusion model should not discourage recognizing how distant corporate and political forms of organizational power can

37. Engel, supra note 8.

38. William Haltom \& Michael McCann, Distorting the Law: Politics, Media, AND THE LITIGATION CRISIS (2004). 
invade local contexts, saturate discourse, and alter opportunities or options in ways that matter for legal rights consciousness and practical action. Horizontal studies of meaning alone strike me as too limiting. An adequate analysis of context and subject position in disputes requires taking power, in all its multiple manifestations and at all levels-local, national, transnational-seriously. In some ways, of course, my point further amplifies Engel's argument that we need both vertical and horizontal approaches, although I am suggesting that they can be combined rather than developed separately.

It is worth noting examples of other studies that make an effort to take power seriously at multiple levels without over-determining topdown influence on individuals in local communities. Gaventa's own powerful sociological study ${ }^{39}$ begins by trying to make sense of why Appalachian workers in one context did not organize to challenge the exploitive work conditions they face, while workers elsewhere did act. His study examines a variety of instrumental, institutional, and ideological forces that together contribute to an absence of resources and opportunities for effective action by locals, to the resigned sense of what he calls "powerlessness." In socio-legal terms, he is explaining why rights mean and matter little to working people in this context. Or consider Gilliom's previously discussed study of poor welfare mothers in Appalachia. ${ }^{40}$ Gilliom's research employed working-class, lower-income women to study welfare mothers in a masterful version of horizontal study. His findings parallel those of Engel in that the welfare mothers found rights a relatively meaningless concept and impractical resource to address their problems of subjugated dependence on invasive, controlling caseworkers. Gilliom describes this powerless position in graphic terms and analyzes how the social context of these women is radically different from those contexts where low-wage women found rights to be meaningful and empowering. In fact, Gilliom explains clearly that virtually all of the many social factors that supported rights activism in my study of pay equity politics were absent for rural Appalachian welfare mothers. ${ }^{41}$

It is not difficult to look outside of the United States for similar efforts. Bernadette Atuahene's recent study of landless rural South African blacks ${ }^{42}$ takes a similar tack in explaining the lack of rightsbased legal mobilization to claim reparations promised by legislation. Athuahene underlines that the promises of rights rang hollow for the subjects she studied in large part because they lack organized

39. GAVENTA, supra note 35.

40. GILLIOM, supra note 13.

41. Id. at 83-92.

42. See Atuahene \& Sibanda, supra note 17. 
associational bonds, political allies, lawyers, money, and knowledge of both legislated entitlements and the means by which they might pursue rights claims. Given their social alienation from governance, rights were somewhere between an empty promise and no promise at all. By contrast, Arzoo Osanloo's fascinating horizontal ethnography of developing everyday rights discourse among women goes a long way toward explaining the factors of social position, social context, state development, and political relationships that nurture development of rights consciousness. 43

All of the subjects in these studies have taken seriously available cultural discourses and relied on ethnographic techniques to investigate rights consciousness and meaning. But the authors have also used tools of social analysis to parse the context of power and position that help to increase our understanding about conditions that nurture more-or less-rights consciousness and their implications for altering power relations. Again, none of these scholars is trying to build predictive causal theory; the goal instead is to analyze how social organization and power condition experience and meaning construction in complex, varying ways. The studies exemplify the type of horizontal research that Engel celebrates, but their attention to power and context goes a step or two further in linking meaning to power and context. This enterprise is equally important, but even more challenging amidst the processes of global economic and political change.

\section{Beyond Quantity: The Variable Content of Rights Consciousness}

The preceding discussion leads to my final point. Engel's Article focuses almost exclusively on horizontal study of differences in how much or how little variously situated subjects find meaning in rights, or how much rights figure into the subjects' legal consciousness. Engel's discussion implies a general assessment about how much rights matter on a single-poled continuum; one presumes that different studies would register like a sliding dimmer switch, from high to low to none. However, most of the studies that I have invoked of ordinary, or subaltern, persons fighting over rights, underline the variability in the content of rights constructions as much as the degree of their salience. The evidence suggests that meaningful investments of many citizens in rights very often do not entail agreement with official law or the neoliberal versions endorsed by transnational actors, political elites, and some scholars. For one thing, most sociolegal scholars assume that rights are not discrete, insular constructs, but rather they are

43. See Arzoo Osanloo, The Politics of Women's Rights In Iran (2009). 
contingent, unstable, context-specific, and often take different meanings in different life circumstances. Rights constructions routinely are mixed with and shaped by various religious, professional, moral, subcultural, and other discursive elements. While people in different places may invoke women's rights or workers' rights or rights to association, for example, the meanings of those claims almost surely will vary from place to place, and at different times.

This is illustrated brilliantly by Lovell's study of rights claims made by variously situated ordinary Americans writing letters to the Civil Rights Division in pre-WWII. ${ }^{44}$ Simply put, the letters reveal an extraordinary range of rights claims and discourses, often merging moral, religious, and local norms into the constructions of rights entitlement, the great majority of which were viewed as far outside the authorized legal rights discourse by officials. Hence, Lovell's title invokes the familiar official refrain: This is Not Civil Rights. This point is also illustrated extremely well by Osanloo's compelling ethnography exploring the hybrid of Western human rights and Islamic religious traditions that animate women's rights consciousness in Iran. Indeed, many scholars have argued that the meanings of rights are likely to proliferate as global forces and local mobilization continue. ${ }^{45}$

Studies of open dissent and challenge often make the variable content of rights claims and meanings a central point of study. For example, I devoted a chapter to exploring the wide-ranging nuances of rights consciousness that interviews revealed in my study of women pressing for rights to equitable wages. Nearly all, very self-consciously, departed from and challenged-sometimes quite radically-rights constructions in official judicial rulings. The women's understandings of gender, markets, equality, fairness, difference, and sameness, along with other component features of antidiscrimination rights, routinely rebuked the neoliberal rhetoric of judges, who were often accused of "not really understanding law." Moreover, one of the most interesting features of the Filipino immigrant workers we presently are studying is the wide range of cultural traditions and sources-from Filipino traditions of anticolonial dissent, American literary radicals, European socialist thought, Marxism, and Maoism-that fused into the growing investment in a radical human rights ideology to challenge liberal and neoliberal American ideas in U.S. courts and other legal institutions.

44. George Lovel, This is Not Civil Rights (forthcoming 2012).

45. See Boaventura de Sousa Santos, Beyond Neoliberal Governance: The World Social Forum as Subaltern Cosmopolitan Politics and Legality, in LAW AND GLOBALIZATION FROM Below: Towards a CoSmopolitan Legality 29 (Boaventura de Sousa Santos \& César A. Rodríguez Garavito eds., 2005). 
One implication of my earlier argument urging horizontal study of widely varied populations thus is an expansion in our understanding of the vast array of constructions and meanings that are associated with rights around the world, including within the United States. We should look for rights everywhere, but we should no more presume that expressions of rights will convey singular meaning than, as Engel warns, presume that rights have any meaning at all for many people in various social circumstances and times. The legal consciousness of people in ordinary, everyday life, at all levels of social position, is likely to be extremely varied. Moreover, we should expect that these assorted meanings often diverge from and even challenge prevailing, authoritative forms of Western liberal rights in subtle or even dramatic ways. Rights talk can, after all, be counter-hegemonic as well as supportive of hegemony. And it often is among those groups who most suffer from dominant relationships and their allies that we might expect such challenging constructions of rights, at least when they do not give in to resigned powerlessness. ${ }^{46}$

\section{E. Local Communities Amidst the Circuits of Power in a Global World}

All of these points become, I suggest, even more salient in situations where harms are identified with the forces of global capitalist integration and imposition. I use a forthcoming book ${ }^{47}$ by my colleague Angelina Godoy to illustrate a more expanded, multi-level version of horizontal analysis. Godoy's study concerns the responses to intellectual property (IP) protections in negotiated trade agreements (especially the Central American Free Trade Agreement) for corporate drug production and sales monopolies that reduce affordable access to necessary drugs for locals in their own communities. Godoy builds her study from the horizontal perspective of interviewing community members and their local representatives in select Central American nations about their relationships with an extremely complicated, ever-shifting array of capitalist corporations, neoliberal organizations like the World Bank, human rights NGOs, local progressive health activists, and actors at the nation-state level. Godoy variously deals with the dynamic, ever-

46. One core implication of my argument is that equating all rights talk with the "imaginary of neoliberal culture" may be overbroad and underspecified. That said, a useful counterpoint to my own wariness in this regard is PETER FITZPATRICK, THE MYTHOLOGY OF MODERN LAW (2002).

47. Angelina Godoy, Writing Globalization's Rulebook: Health, Human Rights, and Intellectual Property in Central America, 2011 (unpublished manuscript) (on file with author). 
changing relationships among these actors advancing their cause in terms of both relative institutional power and varying ideological constructions of rights. At the most general level, she shows that the costs to health care because of multistate negotiated trade agreements are far too indirect and causally complex to fit the traditional model of state-inflicted violence against innocent victims in civil society-in short, the types of harms that liberal human rights conventions developed a reputation for effectively challenging in earlier decades. Indeed, many state actors who were part of the developing transnational capitalist elite became complicit in negotiating and implementing the terms of the harmful new trade policies on behalf of free-market rights and the public good.

Godoy does find that rights figure prominently among local people and a host of other parties who become involved in the dispute. In the early stages of the intellectual property debates, Godoy shows a basic disconnect developed between locals in various countries, who viewed commitments to health rights as a matter of community planning for social justice, and transnational human rights actors, who tended to focus on technical experts and doctors fighting disease. This disjuncture in general orientations to rights was paralleled by disconnects between the responses of NGOs and local progressive activists to new IP agreements and the costs that they imposed, especially on the goal of increasing access to generic drugs. Meanwhile, in some countries like Guatemala and Costa Rica, rights claiming and formal litigation by locals to increase access to expensive drugs increased dramatically in an effort to develop local solutions. While many litigants won in court, however, litigation of individualized rights claims occurred in ways that actually ended up extending corporate control and impeding development of coordinated state policies that might deal with the structural issues in terms of social rights.

Godoy concludes with a rich discussion about the complexities of the supposed clash between human rights and free trade versions of IP policy. Not only has the free trade position of corporations been more cynically imperial than neoliberal, Godoy argues, but she also traces a divergence of human rights approaches to the issues. In particular, she underlines the development of a more social rights vision of state responsibility that grew from Latin American local rights traditions and clashed with the more libertarian, anti-statist type of human rights popular in the Global North. In recent years, Godoy shows, there has been something of a realignment of key NGOs with these more social justice oriented grassroots visions of rights that provide some reason for hope, although the institutional mechanisms for leveraging these rights conceptions into counter-hegemonic power remain elusive. In short, she 
shows an opposite direction in the flow of transformative influence, as NGO groups altered their constructions of rights in ways that were responsive to the traditions of the local grassroots community. My key point here, however, is that Godoy connects a horizontal study of local rights construction over time with a variety of both organizational actors and competing rights constructions at the transnational and state levels. Her study is a superb example of horizontal analysis that begins locally but expands the horizons of relational power, institutional context, and dynamic, ever-changing reconstructions of rights meanings.

\section{CONCLUSION}

I conclude by underlining my strong endorsement of David Engel's analysis exposing the problematic assumptions of a vertical, top-down approach to the diffusion of rights and the often confident faith espoused by some policy elites and scholars that liberal rights talk is a beneficial advance for all, or even most, people and situations. I also want to heartily endorse what Engel calls the horizontal approach to careful study of legal consciousness that is grounded in ethnographic, interview-intensive methods and not biased by presumptions about expected findings-especially those findings that verify vague assumptions regarding the spread of a uniform, Western, neoliberal rights consciousness. But my reflections also have underlined that we need to cast our nets of horizontal inquiry broadly to multiple groups of actors and, in the process, to develop more refined frameworks for specifying social position, analyzing social context, and parsing interdependencies of power at local, national, and transnational levels. In this way, we can expand, thicken, and render more comparatively oriented and interactive knowledge about the legal consciousness of differently situated subjects and the wide variations in the degrees of commitment to rights, in the content of rights that they construct, and in how these constructed practical meanings do or do not figure into processes of social change. 